\section{Psiquiatras chilenas: pioneras en la locura}

\author{
Susana Cubillos Montecino y \\ Angélica Monreal Urrutia
}

Viña del Mar, 18 de octubre de 2013

En primer lugar es un honor para mí poder transmitir algunas breves palabras respecto al libro "Psiquiatras chilenas: Pioneras en la locura". $\mathrm{Al}$ revisar este magnífico y novedoso manuscrito dedicado en honor a estas mujeres vanguardistas, ciertamente adelantadas para su época, me percaté que todas ellas, además de ser colegas psiquiatras, cada una ha aportado, en lo profesional, un granito de arena trascendental para nuestro quehacer clínico-académico en la salud mental chilena.

Los contenidos recopilados mediante agudas y amplias entrevistas, le otorgan un sello muy entretenido que, a modo de crónicas, proporcionan información de las contingencias históricas y anecdotarias de respetables protagonistas con los cuales el lector ha estado familiarizado y que aún se encuentran vigentes.

En sus semblanzas de vida personales, algunas han rememorado tiempos pasados placenteros y alegres y otras han debido realizar profundos sacrificios y concesiones, permitiéndoles empoderarse ante las vicisitudes y desarrollarse como profesionales con fortaleza y lucimiento.

¿Cuáles son las características personales comunes a todas ellas y que les han permitido sobresalir en su ámbito?

Indudablemente, entre sus rasgos sobresalientes, además de un intelecto brillante, destacan el idealismo, que las ha motivado a luchar por sus sueños, sin que nadie hubiese debido recordárselo; la fortaleza, como una roca, en cuanto a sentimientos y conexión empática y aunque a veces parezcan muy frágiles, han sido capaces de defender a ultranza lo que han amado; la valentía, que las ha acompañado en la trayectoria de sus carreras desde sus inicios, sea a nivel nacional o internacional; la dedicación en su formación como especialistas, mediante la cual han perseverado contra viento y marea para alcanzar las metas ambicionadas; el altruismo, traducido en la generosidad y nobleza en su entrega con los pacientes y discípulos; la sabiduría, que les ha posibilitado alcanzar la maestría para resistir los albures propios de su género en momentos más complejos que los actuales para que una mujer profesional se desempeñara y sobresaliera en su campo.

A la aridez, rigurosidad, insensibilidad, competitividad del ejercicio de la especialidad en el mundo médico, aun en muchas oportunidades hostil, ellas han colocado un sello de feminidad, sinónimo de delicadeza, dulzura, amor y ternura.

Son todas mujeres que enaltecen el género, con un alma femenina inspiradora, admirable y digna de imitar como paradigma de una mujer aguerrida y erudita; y por qué no manifestarlo, yo también me he sentido con orgullo reflejada en ellas. Tal vez, con su impronta pudiesen haber hecho suyas las palabras de la afamada escritora británica Virginia Woolf: "No hay barrera, cerradura ni cerrojo que puedas imponer a la libertad de mi mente".

Creo que esta obra, altamente recomendable, puede considerarse un patrimonio histórico y un verdadero tesoro de testimonios documentados de una etapa de nuestro país que ciertamente contribuirá a incrementar los anales legendarios de la psiquiatría chilena.

Para finalizar, me gustaría invocar la sentencia de Novalis, poeta alemán del siglo XVIII, que dice: "La mujer es un amable secreto, no hermético, pero sí velado".

Mis sinceras felicitaciones a las diligentes compiladoras y a las ilustres actoras de este texto. ¡Mucha suerte!

Dra. Rosa Behar A. 